\title{
A Study of Pragmatic Functions of Fuzziness in News Reports from the Perspective of Adaptation Theory
}

\author{
Yun Lian \\ Shanxi Normal University, 041004, China
}

\begin{abstract}
Accuracy is one of the biggest features of news reports, but in fact, we often note that news reports will use a lot of fuzziness, which plays an important role in these news reports. Grounded on Verschueren's adaptation theory, mainly choosing the representative news reports of China Daily and USATODAY as an example, this paper analyzes the pragmatic functions of fuzziness in news reports and illustrates the rationality of fuzziness in theses news reports and reveals that appropriate use of fuzziness in news reports is conductive to the rigor and accuracy of news reports.
\end{abstract}

Index Terms - pragmatic functions, fuzziness, news report, Adaption Theory

\section{INTRODUCTION}

News report plays an increasingly important role in people's life. It is not only a tool of delivering information, but also as necessary linguistic materials of linguists who can do further study for readers to deeper understand news reports. Fuzziness is one of the most significant writing methods in news reports. L.A.Zadeh was the first one to raise aspects of "fuzzy set". In 1965, he published his famous article Fuzzy Set with aspects of the so-called fuzzy set theory. After that, there are many scholars continue to talk about the fuzziness, of course, different scholars have different opinions about the fuzziness. Based on different concepts and different classifications of fuzziness and combined with the theories of cooperative principles and politeness principles, people interested in this field began to do the relevant research. However, this research mainly focuses on the pragmatic functions of fuzziness in news reports based on adaptation theory. To be specific, it aims to answer the following research questions: 1) How is fuzziness used in news reports to adapt to the mental world? 2) How is fuzziness used in news reports to adapt to the physical world? 3) How is fuzziness used in news reports to adapt to the social world? 4) How does fuzziness implement its pragmatic functions in news reports?

\section{LITERATURE REVIEW}

\section{A. Studying of Fuzziness Abroad}

L.A.Zadeh was the first one to raise aspects of "fuzzy set". In 1965, he published his famous article Fuzzy Set with aspects of the so-called fuzzy set theory which made the foundation of fuzziness research. From his article, we found that not all objects had clear-out boundaries, which played a significant role in realizing the fuzzy language. Lakoff(1972) believed that the concepts of natural language are vague, their boundaries are not clear. With illustrating the variable curves when "very", "sort of", "pretty", and "rather" were added to an original fuzzy word, he concluded that the membership of the original word changed in various degrees when different hedges were used. Hedge is one kind of fuzzy language and Lakoff's study made great contribution to fuzzy language study from semantic and grammatical perspective. In addition, Kempson discussed semantic fuzzy language by writing Semantic Theory in 1977. In 1995, Thomas concluded the pragmatic functions of fuzzy language. He pointed out that fuzziness made people's language more or less interesting, besides, he also said that fuzziness can strength the force of one person's message and make more polite and face-saving. What's more, Jueker, Smith and Ludge (2003) also put forward that fuzziness appears in many situations for different purposes in our daily communication, which is almost a common phenomenon.

\section{B. Studying of Fuzzy Language at Home}

In order to fully know about the dynamic researches of hedges in recent 10 years at home, I have looked through National Knowledge Infrastucture (NKI). Surprisingly, there are quite a few core journals discussing about fuzziness and not too many articles about fuzziness. For the sake of clear review, I have made a table between core journals and articles from 2007 to 2016. 


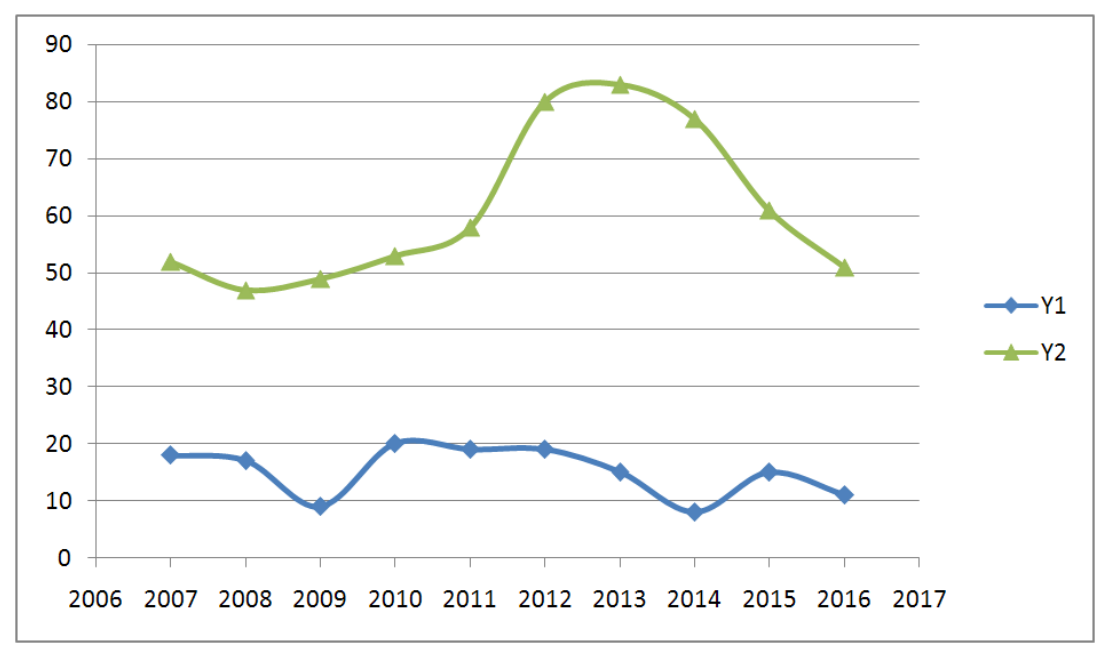

Y1 stands for the number of core journals about fuzziness researches, while Y2 stands for the number of papers including master and doctor about fuzziness researches.

From the table, we can see that basically there is a stable trend of researches fuzziness, but between 2012 and 2014 , especially 2013, the researches of fuzziness reached the summit. Besides, there is no big gap between the lowest and the highest. In contrast, the number of core journals is relatively less.

Next, I will review the studies of fuzziness during ten years at home. About the fuzziness, theses researches can be generally classified the several aspects. Grice (1975) stated that remarks used by speakers wanted to be understandable in a particular conversation, speakers must adhere to some maxims: the maxim of quality, the maxim of quantity, the maxim of relevance and the maxim of manner. The Grice called these maxims Cooperative Principle. As the complementary of cooperative principle, in 1978, Brown and Levinson proposed the Politeness Theory, and then developed by G.N. Leech. Based on his observation, Leech (1983) proposed the Politeness Principle, which helped to explain why people tended to use fuzzy language to express their intentions indirectly. Based on these two theories, many scholars have done the relevant research. Wang (2008) analyzed hedges in American Journalistic English in the basic of cooperative principle and conversational implicature. He showed that news requires the expression to be objective, timely and accurately, while hedges get the features of indirectness, cancelbility, markedness and indefiniteness. From the pragmatic perspective, hedges in journalistic English have certain position and characteristics. Zhao(2009) conducted a study of fuzziness in news based on the cooperative principle, relevance theory and politeness theory. She pointed out by violating Grice's cooperative principle in news fuzzy language is in order to follow another principle. Using fuzzy language in news report is also a way of protecting speakers' face and performing some pragmatic functions. At the same time, Li (2009) also did the similar research but the difference is combining the diplomatic language with cooperative principle and speech act theory. Li (2009) said the diplomatic language is normal, conservative and accurate language and it needs to pay attention to the language strategy. Speakers intentionally used some vague language to strengthen the language flexibility and make language expression more political and implicit.

But quite a lot of scholars broke through the previous theories, especially cooperative principle and politeness principle, and found relevant new theories such as the theory of adaption and the relevance theory. In 2008, Zhang Junyi did the analysis about fuzziness in news language and it adaptability. He pointed that accuracy is the important requirement for news report, but Verschueren's Adaptation Theory may offer a sound explanation why fuzzy language existed in news report. Song (2010) attempted to give a detailed analysis of the adaptation of vague language in English news discourse and found that the application of vagueness in English news discourse results from choice making in communication. Her study may provide us some experience to further study. Of course, Zhu(2011), Zhao(2011), Jie(2012), Jiang(2016) also did the different researches based on adaptation theory. Both Jiang (2016) and Jie(2012) conducted a contrastive study of hedges in political aspect.

\section{DEFINITION OF FUZZINESS AND THEORETICAL FRAMEWORK}

\section{A. Definition}

Wu Tieping, professor in Beijing Normal University, is the founder to introduce fuzzy-set theory into China. In 1979, professor Wu published his famous article The Elementary Research on Fuzzy Language, which was the first article about fuzzy linguistics in China. Meanwhile, he has published articles about fuzzy words, fuzzy concepts and the relationships between fuzzy words and terminology, lexicology, etc, covering a wide range of the research about fuzziness in Chinese. He paid much attention to fuzzy words, for instances, words indicating time, color, size, age, etc. Based on the previous researches on classification of hedges, professor Wu divided the hedges into the following four types with three standards:

1. The first classification is according to the words they will modify. 
a. Hedges modifying only fuzzy words:

Very beautiful, essentially generous

b. Hedges modifying both fuzzy words and precise words:

Highly prestigious, close to the beginning point, about 8 o'clock

2. The second classification is according to grammatical categories or parts of speech.

a. Words: adv. Very, actually

Adj. regular

b. sweetish

c. Conjunctions: so...that

d. Phrases and clauses expressing subjective ideas: I think, according to...(one's impression, one's address...), etc

3. The third classification is according to upper or lower limit of hedges.

a. The upper limit is determined, whereas the lower limit is not. For instance: very tall

b. The lower limit is determined where the upper limit is not. For instance: a little bit tall

c. Neither the lower nor the upper limit is determined. For instance: not tall and not short, not fat and not thin

Professor Wu (1979) introduced fuzzy-set theory into China and had done many researches about it, which offered us a general introduction about fuzzy language in China. Fuzzy theory, hedges and vague language went in to a new era in China. Though the study is still rooted in semantic category, from then on, a lot of domestic researchers have been interested in the study of hedges. It is also the basis for using of hedges in pragmatics and discourse analysis.

\section{B. Theoretical Framework}

Adaption theory was first referred by Verschueren in his thesis "Understanding Pragmatics" in 2000. In the theory, he pointed that the use of language is that speakers make their choices constantly in order to adapt the need of communication because of internal and external language reason. According to Verschueren's theory, it should link linguistic features and other discourse environments because language has three features: variability, negotiability and adaptability. These three features connected with each other. Variability refers to that there are a series of choices can be chosen in language using. Negotiability refers to choose a certain language grounded on some pragmatic principle and pragmatic strategies; while variability and negotiability provides necessary conditions for adaptability that refers to language users can make different flexible choices to satisfy different communicative needs. As an important theory of linguistic theory, adaptation theory has provided a new perspective for studying of language phenomenon.

More importantly, in order to achieve communication purpose, both sides have to adapt both language contexts and communicative contexts. From the perspective of adaptation theory, contextual correlates of adaptation means communicative contexts. In Verschueren's opinion, contextual correlates of adaptability include all the elements in the communicative context which involve aspects of the physical surroundings and of the interlocutors' state of mind as well as social relationships between addressers and interpreters. Then we will talk about communicative from three aspects.

\section{The Mental World}

Mental world is about the language users' psychological factors, including language user's emotion, characteristics, beliefs, motivations, intentions and so on. Cognitive factors and emotional factors are two main categories of communicative context. The process of language users' choosing language is the flexible process of adapting to the mental world of utters and interpreters.

\section{The Social World}

It seems to that the language choice is closely related to social elements. The social world concerned about social environment, social principle and social standards. Versehueren(2000) pointed that some social factors affect linguistic choice, such as nationality, race, religious, education level, age, gender and so on. Besides, linguistic choice can also affects social relation or social power. Therefore, in order to achieve a success communicative purpose, the language users have to adapt the social world by choosing different language.

\section{The Physical World}

There are two fields were included in the physical world, that is, temporal reference and spatial reference. Specifically, it is a context including time, space, topics and so on. According to Versehueren's theory, the physical world contained factors such as language users, topic, target, gestures, bodily postures, physical appearance, biological property and so on. If any element of them is changed, it will lead to different certain psychological states. Of course, it will influence the language choice and communication form.

\section{PRAGMatic FunCtions OF FuZZINESS}

Adaptation theory attempts to seek the human language communication mechanism and role of society and certain culture background to reveal various phenomena appearing the human language. Fuzziness is the nature of language. Certain fuzziness used in news reports plays an indispensible role which is beneficial to individual, society and even a country to better understand them. Adaptation theory offers a methodology basis to analyze the news reports. It has broad effect in pragmatic field.

\section{A. Adaption of Mental World}




\section{Adaption of Reader's Interest}

Example1: More than 3,000 Tibetan antelopes stopped under the shadow of the Wudaoliang North Bridge on the Qinghai-Tibet Railway. After a few hesitant minutes, the antelopes passed through the shadow to continue their migratory journey.

(China Daily, Oct. 5, 2017)

As it is shown in example 1, these expressions "more than" and "a few" are fuzzy expressions that are enough to adapt reader's interest. This news report is about the environmental problem of Tibet, however, when readers pay attention to "more than 3,000 antelopes" and "a few hesitant minutes", they may think that what happened with antelopes. Reporters use fuzzy expressions to attract readers' reading need and to get the value of news report. More importantly, news reports like this attain the purpose of calling people to protect environment.

2. Adaption of Reporters' Self-protection

Example 2: The officials said the two wounded were taken to Niamey, the capital, and are in stable condition. The officials were not authorized to discuss the incident publicly so spoke on condition of anonymity.

Example 3: The White House said President Donald Trump was notified about the attack Wednesday night as he flew aboard Air Force One from Las Vegas to Washington. Trump was in Las Vegas meeting with victims of Sunday night's shooting massacre, along with first responders and doctors.

(USA TODAY, Oct. 4, 2017)

Both "The official said" and "The White House said" in example 2 and example 3 are fuzzy expressions. The reporters use these fuzzy expressions to report news, one the one hand, which illustrates that the news is from official or important organizations and it is real and objective; on the other hand, this avoids reporters from any responsibility if information is not correct.

\section{B. Adaption to Social World}

A lot of social factors are included in social world. This article just focuses on adaption to political group and adaption to negative influence on society.

1. Adaptation to Political Group

Example 4: We BRICS leaders believe that practical cooperation is the root of BRICS cooperation.... Thanks to our efforts over the past year, we have made new strides toward greater connectivity in trade, investment, currency and finance, and infrastructure. We all stress the need to place more emphasis on innovation, seize the historic opportunities offered by the new round of industrial revolution and improve economic structure at a faster pace so as to secure more resilient, sustainable and quality growth for all.

(China daily, Sep. 5, 2017)

This is about the Xi's remarks at the press conference of the BRICS Xiamen summit. Although it is about of the remarks of Xi's, however, the fuzzy expression "we BRICS leaders believe..." is used, which is a strategic method to achieve the successful communicative purpose. Besides, "the past year" "greater connectivity" "more emphasis" "historic opportunities" "more resilient, sustainable and quality" all of these fuzzy expressions are properly used in political situation, which expresses the high expectations of President Xi standing for China, and adapting the standards of language use in news report.

Example 5: In his message, Xi extended deep sympathy to the US government and people, profound condolences to the victims and sincere solicitude to those wounded, and said he wished for a quick recovery for the injured.

(China Daily, Oct. 4, 2017)

It is about $\mathrm{Xi}$ sends condolence to Trump. We know there are complex relationships between countries. President $\mathrm{Xi}$ stands for a country sending the condolence to Trump after happening of mass shooting in Las Vegas. By using fuzzy expressions "deep" "profound" "sincere" "quick", it is not only expressing the President Xi's real emotion, but also adapting the national situation.

2. Adaption to Avoid Negative Influence on Society

Example 6: It was happening: A mass shooting that would turn out to be the worst in U.S. history. And she was standing in the middle of it.

The volley of gunshots lasted just 11 minutes. But in that span, Stephen Paddock, 64, a chronic gambler, real estate investor and former mail carrier from Mesquite, Nev., operating from a 32nd-floor perch in a glass-clad high-rise hotel, used a small arsenal to kill at least 58 people and wound more than 500.

Paddock brought with him "in excess of 10 suitcases," according to police. The cases held at least 23 weapons, many of them rifles ranging in size from .308 to .223 caliber, along with two tripods.

(UAS TODAY, Oct. 5, 2017)

It is about Las Vegas mass shooting report. The disaster news is naturally not good news for all of the people. Therefore, proper use of fuzzy language can avoid some negative effect on society. Fuzzy expressions including "mass" "at least" "more than" show that this shooting is so heavy and so bad, but using them can adapt the habits of news report expressions trying to reduce the harm of disaster for people.

\section{Adaption to Physical World}

Excepting temporal references and spatial reference are included in the physical world, other factors such as physical 
appearance, postures, biological property are also included. Spatial reference largely focuses on certain spatial relationship such as south and north, while temporal reference includes event time, reference time, and so on.

1. Adaption to time

Example 7: "(China's) GDP growth is revised upward in 2017 in light of better-than-expected performance in the first half of the year," the World Bank said in its latest East Asia and Pacific Economic Update.

(China Daily, Oct. 5, 2017)

It is about the World Bank now expects China's economy to expand in 2017. In this news report, "in the first half of the year" is the fuzzy expression, and as a piece of news it is not necessary to report exactly time, that is not to saying that fuzzy expression like this will influence the accuracy of news report instead of this fuzzy expression giving readers a total conception that China's economy has expanded than before. It is appropriate to use this fuzzy expression in this news report because it adapts the expression of time in news report.

Example8: Just after 10 p.m. Sunday, Michelle Compton was enjoying herself, listening to the act she'd come all this way to see: Jason Aldean, the night's headliner at the Route 91 Harvest festival.

A few doors down from Paddock, Sonny Morgan, an Atlanta-area businessman in town for a conference, dozed in front of "Sunday Night Football" when he woke to the sounds of gunshots.

The shooting stopped momentarily, but when it picked up again, around 10:21 p.m., one officer reported that he saw a "strobe light" coming from the hotel's north tower.

(UAS TODAY, Oct. 4, 2017)

It is about Las Vegas mass shooting report. In this news report, "after" "around" are both fuzzy expressions. Because of this report about important shooting event that almost every person will pay attention to, using fuzzy expressions satisfy readers' need. Like this report, no one knows what exactly time it happened. The use of fuzzy expressions is adapting the standards of news report: quick and immediate.

2. Adaption to Space

Example9: JERUSALEM - A Palestinian gunman killed three Israeli security officers and wounded another outside a West Bank settlement on Tuesday morning before he was shot dead, Israeli police said.

The shootout took place outside Har Adar, an upscale Jewish settlement northwest of Jerusalem, near the seam zone between Israel and the Israeli-occupied West Bank.

(Xinhua, Sep. 27, 2017)

The news reports require to be timely, so if there is an important event, reporters have to report. In this example, maybe reporters don't have accurate address, so they use fuzzy expressions instead, such as "outside" "northwest". These expressions are not losing news value rather than adapting the news characteristics that people can get the firsthand material quickly.

\section{CONCLUSION}

Although accuracy is one of the most important features of news reports, however, this article shows that proper use of fussiness in news reports can adapt pragmatic principles and communicative principles, which can spark a strong performance of news reports, such as simpler, more balanced, more implicit. Analyzing the proper use of fuzziness in latest news reports grounded on adaptation theory is not only providing a new perspective for pragmatics study, but beneficial to people better understanding the news reports.

\section{REFERENCES}

[1] Brown, P. \& S. C. Levinson. (1978). Politeness: Some Universals in Language Use. Cambridge: Cambridge University Press.

[2] Grice, H.P. (1975). Syntax and Semantics. New York: Academic Press.

[3] He Ziran. (2003). Notes on Pragmatics. Nan Jing: Nan Jing Normal University Press.

[4] Jiang Hongyi. (2016). A Comparative Study of Vagueness in English and Chinese Diplomatic Speakers Based on Adaptation Theory. Ph.D. dissertation, Changchun University of Science and Technology.

[5] Jie Feifei. (2012). A Constructive Analysis of Hedges in English and Chinese Political News Reports. Ph.D. dissertation, Henan Normal University.

[6] Jing Pengsun \& Jiao Yanan. (2011). A Pragmatic Interpretation of Vagueness in News. Foreign Teaching and Research, 194, 193-194.

[7] Jucker A. H., Smith. \& Ludge. (2003). Interactive Aspects of Vagueness in Conversation. Journal of Pragmatics, 69, 35-37.

[8] Kempson, R. (1977). Semantic Theory. Cambridge: Cambridge University Press.

[9] Lakoff, G. (1972). Hedges: A Study in Meaning Criteria and the Logic of Fuzzy Concepts. Chicago: Chicago Society.

[10] L. A. Zadeh. (1965). Fuzzy Sets, Information and Control. New York: Academic Press.

[11] Leech, G.N. (1983). Principle of Pragmatics. London: Longman House.

[12] Li Chao. (2009). A Pragmatic Study of English Vague Language in Diplomatic Language. Ph.D. dissertation, University of Jilin.

[13] Lv Shujing. (2014). A Study of Vague Language in English Editorials Based on Adaptation Theory. Ph.D. dissertation, Shandong Normal University.

[14] Ma Jingsai. (2014). A Study of Pragmatic Functions of Fuzziness in Disaster News Texts from the Perspective of Adaptation Theory. Ph.D. dissertation, Hebei United University. 
[15] Song Xin. (2010). An Adaptability-theoretic Approach to Vagueness in English News Discourse. Ph.D. dissertation, Shandong University.

[16] Sun Lianzhong \& Gao Wei. (1990). Fuzzy Linguistics. Shan Xi: Shan Xi People's Press.

[17] Thomas, J. (1995). Meaning in Interaction: An Introduction to Pragmatics. London: Longman.

[18] Verschueren,J.(2000). Understanding Pragmatic. Beijing: Foreign Language Teaching and Research Press.

[19] Wang Lianlian. (2008). The Pragmatic Analysis of Hedges in American Journalistic English. Ph.D. dissertation, Shandong Normal University.

[20] Wu Tieping. (1979). the Research of Fuzzy Language. Foreign Language Journal, 4, 39-44.

[21] Yang Zijian. (2002). Multidisciplinary Research and Application of Language. Guang Xi: Guang Xi Educational Press.

[22] Yue Wenhua. (2012). Pragmatic Analysis of Vague Language in Disaster News. Overseas English, 7, 261-262.

[23] Zhang Junyi. (2008). Fuzziness in News Language and Its Adaptation Analysis. Ph. D. dissertation, Shanghai International Studies University.

[24] Zhao Ai. (2011). A Pragmatic Study of Vague Language in English Political Discourse from the Perspective of Adaption Theory. Ph.D. dissertation, Dongbei University of Finance and Economics.

[25] Zhao Lijuan. (2009). Fuzziness in News: A Study from Pragmatic Perspective. Ph.D. dissertation, Shangdong University.

[26] Zhu Kui \& Wu Junzan. (2011). Contextual Adaptation of Hedges. Foreign Language and Literature, 12, 52-53.

Yun Lian was born in Shanxi, China in 1991.

She is currently a postgraduate in the school of Foreign Language, Shanxi Normal University, Shanxi, China. Her research interest is mainly pragmatics. 